\title{
Publicando Lolita. Comentário do Prefácio de John Ray, Jr., ph.D.
}

André Rangel Rios

Recebido em 15/07/2011 - Aprovado em 01/09/2011

\section{Resumo}

O artigo considera o "ato" de publicação de um modo amplo, ou seja, como um "processo" de publicação, que envolve vários estágios, desde a formação e habilidade linguística do escritor, passando pela publicação material do livro e estratégias para evitar censura e processos judiciais, até a recepção pela crítica e público; a ênfase deste artigo, no entanto, recai na análise do ato de publicação e de escrita enquanto mencionados ou aludidos na própria narrativa, ou seja, enquanto entretecidos na própria realidade ficcional. Assim, partindo-se do comentário do Prefácio de Lolita, assinado por John Ray, Jr., ph. D., são apresentadas estratégias argumentativas dos autores ficcionais em favor da não proibição do livro, bem como alguns importantes aspectos da intrincada relação entre, por um lado, John Ray Jr. e Humbert Humbert, dois escritores imanentes à própria trama narrativa, e, por outro, o autor signatário, Vladimir Nabokov, expondo, entre outras coisas, a consciência da ousadia de sua aposta literária frente ao público da "era da classe média enxerida", bem como sua confiança nos promissores resultados da publicação de Lolita.

Palavras-chave: teoria literária; literatura e medicina; autoria; paranoia; ato de leitura; ato de publicação. 
...I'm sorry I cheated so much, but that is the way things are.

Nabokov, Lolita

A Teoria Literária tem, em diferentes aspectos, discutido principalmente o ato de escrita e o ato de leitura. $\mathrm{O}$ ato de publicação também tem sido um tema, mas é, em geral, abordado em uma perspectiva sociológica, levando-se em conta a origem social dos escritores, a vendagem dos livros e o prestígio das editoras. ${ }^{1}$ Em outros textos, estive considerando o "ato" de publicação de um modo mais amplo, ou seja, como um "processo" de publicação, que envolve vários estágios, desde a formação do escritor, passando pela publicação material do livro e estratégias para evitar censura e processos judiciais, até a recepção pela crítica e público (RIOS, 2007). Minha ênfase, no entanto, tem sido na análise do ato de publicação mencionado ou aludido na própria narrativa ficcional, ou seja, enquanto entretecido na própria realidade ficcional, ${ }^{2}$ explicitando sua coerência ou contradições com a narrativa. Até onde sei, essa minha abordagem do tema, ou ao menos a ênfase que dou a esse aspecto, é original, tendo se mostrado produtiva quanto a propor novas questões. Assim, na leitura de Dom Casmurro, um livro sobre o qual muito da crítica tem girado em torno da obsessão - patriarcal - de quem traiu quem, ao se considerar o ato de publicação, ou mais especificamente, ao se considerar que o livro Dom Casmurro foi publicado intradiegeticamente, novas questões se impõem. Logo de início, no Capítulo 2, Bento Santiago, referindo-se ao próprio livro, alega se sentir envergonhado em publicá-lo: "vexa imprimi-lo" (MACHADO DE ASSIS, 1986, p. 809). O leitor ou leitora deveria estar, portanto, desde o início, consciente de que está lendo um livro que a própria narrativa assume como já tendo sido publicado. No entanto, Bento Santiago também se apresenta no livro como uma pessoa reservada, que esconde dos amigos e de seu círculo social segredos inconfessáveis de sua vida privada. Em geral, leitores e intérpretes aceitam esse perfil reservado do

1 Alguns exemplos importantes de pesquisas sociológicas sobre a temática autor/ escritor/ publicação são BOURDIEU, 1992; MICELI, 2001; LAHIRE, 2006. Na verdade, é somente Lahire que realmente comenta, de modo mais extenso, a questão da publicação.

2 Em especial em relação ao livro Betrachtung, de Kafka, Stach (2003, passim) é um bom exemplo da discussão do processo autor/ editor/ publicação; no entanto, ele não tematiza a publinarrador como autêntico. Ora, o livro está publicado; ou seja, haveria uma contradição performática entre a autodescrição de Bento como sendo um ermitão e sua vida privada tornada pública pelo próprio livro em que ele, ao publicá-lo, se proclama um recluso. Essa contradição, a meu ver, demanda uma releitura de Dom Casmurro (RIOS, 2007, p. 48-84).

Em Lolita, tal como Machado de Assis em seus últimos livros, Nabokov se afasta - ou apenas finge se afastar - da cena da escrita em favor de uma sequência de personagens fictícios, o que, entre outros efeitos que ainda temos de analisar, tornaria mais plausíveis algumas fases da publicação intradiegética do livro (e, talvez, favorecessem sua publicação e aceitação extradiegética). Assim, o livro teria sido escrito por Humbert 
Humbert (que, declaradamente, seria um pseudônimo escolhido pelo próprio autor), um suíço, radicado nos Estados Unidos, que teria morrido na prisão. Os originais de Lolita, seguindo provisões testamentárias, teriam sido passados pelo advogado de Humbert, Clarence Clark, para John Ray, Jr, ph. D., que o teria editado e publicado (no caso, publicado num livro cujo nome do autor na capa é Vladimir Nabokov, o que o prefácio, aparentemente referindo-se apenas a $\mathrm{H}$. $\mathrm{H}$. como sendo o autor, não menciona). Assim, o prefácio que analisarei a seguir não teria sido escrito nem por Humbert nem por Nabokov, mas por John Ray, Jr. (NABOKOV, 2011, p. 10). O prefácio seria uma interface entre o autor ficcional, Humbert Humbert, e o autor signatário, Vladimir Nabokov; no entanto, John Ray é editor e prefaciador enquanto se apresenta como associado à narrativa no corpo do romance, estando, portanto, contido em seu espaço ficcional.

Em termos gerais, o prefácio, ao menos numa primeira leitura, tentaria contornar preventivamente dificuldades como censura, processos judiciais e acusação de ser pornografia (e não obra de arte); ${ }^{3}$ alegações que poderiam ser feitas tanto a respeito da publicação intradiegética quanto da publicação real nas sociedades americana e européia. O prefácio tem, portanto, ao menos duas faces: ele negocia aspectos pertinentes tanto à coerência da narrativa quanto à aceitação do livro escrito por Nabokov para que, no processo de publicação, ele seja reconhecido tanto como publicável quanto como artístico. Além dessas considerações, indicarei mais adiante que o prefácio reverbera questões, ainda mais intrincadas, próprias à estrutura do romance e a suas consequências a respeito da questão da autoria. No presente artigo, comentarei esse prefácio buscando analisá-lo sobretudo como uma parte da narrativa de Lolita.

Assim, analisarei o prefácio a partir de uma questão que, embora óbvia, nunca foi feita: Por que John Ray, Jr. Ph. D., publi-

3 Como já indiquei, nenhuma dessas fases do processo de publicação é considerada em Dom Casmurro.

4 É importante notar que, intradiegeticamente, o livro é considerado como publicado após cumprida essa exigência. No entanto, o que é previsto na narrativa é que Lolita morresse com 80 ou 90 anos: “Em sua forma publicada, este livro está sendo lido, imagino, nos primeiros anos da década de 2000 d.C. (1935 mais oitenta ou noventa, uma vida longa, meu amor); e os leitores mais idosos certamente se recordacou seu prefácio de Lolita? Segundo ele explica, tendo Humbert Humbert morrido na prisão de trombose coronariana, antes de ser julgado por seus crimes, seu advogado, Clarence Clark, seguindo uma "cláusula do testamento" do falecido cliente, deveria encaminhar Lolita para a publicação. A cláusula não é explicitada por Ray, mas ela certamente não se resume apenas ao encargo de que o advogado passasse o manuscrito adiante para que alguém o publicasse; por exemplo, fica bem claro no último capítulo de Lolita, que o livro só deve ser publicado após a morte de Lolita (NABOKOV, 2011, p. 359). ${ }^{4}$ Ray entende que Clark lhe confiou a tarefa de editar o livro por ele haver recebido um prêmio devido a um livro em que discutia perversões. Ray é, portanto, apenas o editor do manuscrito; como já indiquei ser uma omissão usual, nada é diretamente mencionado sobre a aceitação por parte de editoras e do financiamento da impressão e da comercialização. Também não é claro por que a edição do livro seria confiada a 
um premiado estudioso das perversões. Ray parece acreditar que foi uma decisão de Clarence Clark, que ele considera um amigo, mas, sendo Clark o advogado de H. H., deixar a edição (e o prefácio) ao encargo de um especialista "amigo", talvez influenciável pelo advogado, pode ter sido uma determinação do testador. Pode Ray ter a certeza de que não está sendo manipulado pelo "perverso" H. H.? Essa hipótese não parece lhe ocorrer, embora, ao longo da narrativa, $\mathrm{H}$. H. repetidamente escarneça os psiquiatras e psicanalistas. ${ }^{5}$ Seja como for, Ray assume como sua tarefa principal corrigir os "solecismos mais óbvios", que seriam poucos, e suprimir "alguns pormenores" que ainda possibilitassem o reconhecimento dos lugares e das pessoas envolvidas na história, enfim, uma tarefa de ocultação de rastros, já extensamente empreendida pelo próprio H. H. em seu manuscrito; tarefa essa de ocultação que, segundo Ray, deveria ser feita por "discernimento" e "compaixão". Assim, o pseudônimo do autor seria uma "máscara" (NABOKOV, 2011, p. 7). Haze, do nome Dolores Haze, seria apenas mais um pseudônimo, que, no caso, rimaria com o nome verdadeiro. Apenas o prenome Dolores, que estaria "entretecido na trama profunda do livro", é que teria sido mantido, ou seja, por causa das numerosas variantes possíveis de Dolores: Lo, Lolita, Dolly, L., e talvez em especial devido ao prazer oral de falar "Lolita": "Lo-li-ta: a ponta da língua toca em três pontos consecutivos do palato para encostar, ao três, nos dentes. Lo. Li Ta." (Idem, p. 13). Consequentemente, apenas "Dolores" teria se mantido como um vínculo entre narrativa e realidade. Mais uma vez, Ray parece não desconfiar de uma tal afirmação, pois existem muitos nomes em inglês que se prestam ao mesmo jogo línguo-buco-fonológico. Em todo caso, como que para aumentar sua credibilidade, Ray cita eventos que teriam ocorrido após a morte de Humbert para deixar "os leitores mais antiquados" satisfeitos; no entanto, uma vez que nem nós nem os tais leitores antiquados, porque supostamente ainda estamos começando a ler o livro, não conseguimos compreender essas informações que só podem fazer sentido após a leitura completa do livro, podemos apenas ter a impressão de que esses diversos fatos estariam dando continuidade a uma história real, corroborando-a (assim como é feito em filmes baseados em histórias reais, que contam o que aconteceu a cada um dos personagens após o final da trama principal). Seja como for, no prefácio, os nomes muitas vezes aparecem entre aspas, o que indicaria que são nomes fictícios, o que, aliás, não deixaria de sugerir - mas apenas a um leitor já avisado - que o que supostamente veio a se passar com eles seja igualmente fictício:

"Rita" casou-se recentemente com o proprietário de um hotel na Flórida. A sra. "Richard F. Schiller" morreu no parto... "Vivian Darkbloom" é autora de uma biografia... (NABOKOV, 2011, p. 8). 
Enfim, no resto, se nos permitirmos a mesma credulidade de Ray, a narrativa seria real e teria sido escrita por um preso nos 56 dias em que aguardava o início do julgamento. ${ }^{6}$ A seguir, Ray passa a considerar Lolita como "um simples romance" (Ibidem). Seu objetivo é defender que o livro não é obsceno, não contendo nem sequer palavrões; nisso, Ray lembra a "monumental decisão emitida em 6 de dezembro de 1933 pelo meritíssimo John M. Woolsey, com referência a outro livro, bem mais explícito" (Idem, p. 9). Ora, esse livro "bem mais explícito", que, portanto, talvez descaísse "bem mais" para o lado do pornográfico, é o Ulysses, de James Joyce. A argumentação é bicorne: Lolita é comparada a Ulysses, tanto porque seria uma obra de arte, isto é, porque seria - isso, assim me parece, está implícito - uma obra de arte de estatura equivalente, quanto porque não seria pornografia (supostamente devendo ser aplicada também a Lolita a referida sentença); além do mais, seria, de certo modo, uma obra menos pornográfica e - implicitamente (segundo aqueles que aceitem a contraposição arte vs. pornografia) - mais artística. Ora, sendo o prefácio ficcional, ele é um plaidoyer para que o autor do livro, H. H., exerça, porque também é um escritor grandioso, sua liberdade de expressão artística.

No entanto, Ray não nega que $\mathrm{H}$. H. tenha problemas psicológicos e que seja um exemplo de "lepra moral" (Ibidem), embora suponha que, se ele tivesse procurado a tempo um "psicopatologista competente", "a calamidade ["disaster"] não teria ocorrido" (Ibidem); no caso, a "calamidade" é Humbert ter iniciado um relacionamento sexual com Lolita. O problema é que, se tal "calamidade" não tivesse ocorrido, a "grande obra de arte" Lolita, também não teria sido dada ao mundo: "nessa hipótese [sem a calamidade], tampouco existira o presente livro" (NABOKOV, 2011, p. 10). A "calamidade" é entendida por Ray como um pressuposto necessário para a escrita de Lolita.

Assim, Lolita valeria tanto como uma obra de arte quanto como um relato de caso clínico, o que, evidentemente, seria mais um motivo para não proibi-lo, pois - segundo Ray - esse livro "há de tornar-se, sem dúvida, um clássico nos círculos psiquiátricos" (Idem, p. 8). Além disso, como um argumento de menos destaque, Ray alega que o livro teria também "impacto moral" no sentido de que advertiria "contra tendências perigosas" próprias a algumas pessoas como a "mãe egoísta" e o "maníaco ofegante" (Idem, p. 10). O prefácio busca, portanto, assegurar a publicação de Lolita. Suas duas principais linhas de argumentação são, por um lado, uma de caráter estético, porque o livro é uma (grande) obra de arte e tem seu direito de publicação assegurado pela mesma decisão judiciária que permitiu a edição americana de Ulysses e, por outro, uma de caráter jurídico, porque mascarou todos os nomes de lugares e de pessoas que eventualmente poderiam se sentir ofendidas e impedir sua publicação (ou seja, 
que poderiam impossibilitar sua futura consagração como uma obra do porte de Ulysses). Em vista disso, embora o texto não seja claro, a escolha de Ray como editor e prefaciador parece bastante adequada e bem poderia ter partido de Humbert, pois, com o apoio do advogado, que teria assegurado o lado jurídico da exclusão de ocasionais queixosos (reforçando-o com o prefácio de um especialista com argumentos psiquiátricos e literários), H. H. poderia morrer tranquilo quanto a sua fama artística, ainda que, talvez, não sob seu nome verdadeiro. Podemos, em todo caso, afirmar que Ray defendeu com habilidade a obra de Humbert; e, se o fez, é porque aparentemente acreditou nele, tanto como literato (que, de fato, categoricamente, confirma esse status de escritor de prestígio ao descrever sua estada como escritor convidado no Cantrip College) (NABOKOV, 2011, p. 304) quanto como psicopata (que, segundo é narrado em Lolita, teria passado por várias internações psiquiátricas). Numa narrativa que declara ter apagado todos os rastros que possibilitassem sua comprovação, o que podemos ainda voltar a discutir é se Ray não se tornou mais um dos psiquiatras iludidos por "ardilosas pistas falsas" (Idem, p. 42). De fato, Humbert, além de descrever seu zelo pela literatura, ${ }^{7}$ é extremamente preocupado com questões legais; por isso, tentou descobrir qual seria a situação legal entre ele e Lolita, o que, confessa ele autoironicamente, nunca conseguiu saber, porque, devido a suas viagens através de diversos estados americanos, cada um com leis diferentes a respeito do tutor e da tutelagem, nada de unívoco pôde ser estabelecido. No entanto, ele diz ter lido vários livros "sobre o casamento, o estupro, a adoção e assim por diante". Sua conclusão é que, em importantes livros de Direito, casos como o seu não eram sequer considerados e que, em alguns estados da federação, segundo H. H. cita: "Não existe princípio que obrigue todo o menor a ter um tutor; o tribunal é passivo, e só deve interceder quando a crianças estiver exposta a riscos visíveis" (Idem, p. 200-1). Ora, se ninguém o via fazendo sexo com Lolita, então não haveria motivo para o tribunal deixar de ser passivo. No entanto, Humbert afirma com clareza que o inventário referente à mãe de Lolita estava "na mais perfeita ordem" ("in perfect order") e que "as parcas propriedades da mãe morta esperavam intactas a maioridade de Dolores Haze" (Idem, p. 201); enfim, Humbert é escrupulosamente honesto com Lolita. Por isso, é de se espe-

7 Um exemplo: "Estando muito ocupado com meus afazeres literários..." (NABOKOV, 2011, p. 233). O que, como comentarei novamente, abre a possibilidade de considerarmos que talvez, já nesse momento, o livro Lolita estivesse sendo escrito, em vez de ter sido escrirar que Humbert, que se apresenta como um escritor dedicado ao ofício e tem em mente escrever uma grande obra: “...no final das contas eu tinha uma grande obra a escrever..." "I had after all a learned opus to write") (NABOKOV, 2011, p. 106), também tenha deixado disposições de ordem jurídica e prática, válidas e minuciosas, assegurando o máximo possível a publicação de seu "opus" "na mais perfeita ordem". 
Agora é o momento de abordar o prefácio por outro flanco: Por que Nabokov publicou o prefácio de John Ray, Jr., ph. D.? Primeiramente, pode-se supor, também por razões jurídicas. Em segundo lugar, Ray pôde argumentar desembaraçadamente que se trata de uma obra de ficção e, sem precisar pecar diretamente por imodéstia - porque quem assina não é Nabokov -, pôr Humbert (Nabokov?) ao lado de James Joyce ao incensar a perícia literária de Lolita. Além disso, por meio de Ray, Nabokov pôde ser autoirônico ao dizer que retirou os "solecismos mais óbvios"; imperícia em que ele, que estudou em Cambridge, morava e dava aulas nos EUA desde 1941 e já publicara livros em inglês, supostamente não incorreria. No entanto, particularmente importante é o prefácio aumentar a distância entre Nabokov e Humbert Humbert, o autor ficcional do subsequente relato autobiográfico moralmente questionável. Se o texto de H. H. não fosse antecedido por um prefácio, teríamos uma passagem abrupta do nome Nabokov, na capa e na folha de rosto, para o texto autobiográfico de um pedófilo e assassino confesso, sugerindo que, talvez em alguma medida, Lolita tivesse algo da vida do autor signatário e detentor dos direitos autorais (afinal, há várias similaridades entre esses dois europeus cultos, universitários, herdeiros, viajantes pelo interior dos Estados Unidos, acolhedores do inglês como língua literária, expatriados e estabelecidos em Nova Iorque mais ou menos na mesma época). Ao mesmo tempo, ao se afastar da escrita de H. H., que, supostamente, até recairia em solecismos óbvios, Nabokov, enquanto autor signatário, passa a impressão de ter prodigiosamente conseguido entrar na mente de um perverso, o que muitos leitores, corroborados pelo especialista John Ray, supõem que ele fez. Será que ele o fez? Ou será que ele apenas se divertiu convencendo seus leitores que o fez, tal como $\mathrm{H}$. $\mathrm{H}$. se divertia fazendo os psiquiatras acreditarem em suas "falsas pistas"? Apesar dessas possíveis questões, pode-se dizer que as manobras intradiegéticas em prol da publicação de Lolita são, no geral, bem convenientes para ajudar no previsivelmente difícil processo de publicação extradiegético do livro. No entanto, há questões mais radicais que já assombram o prefácio: em especial, o nome "Vivian Darkbloom", que já apareceu numa citação logo acima neste artigo, e que, como mostrarei mais abaixo, subverte as relações autorais intra- e extradiegéticas.

Antes de me aprofundar nessa questão, vou, porém, retornar a mais um aspecto do relato de Humbert Humbert. Segundo ele alega, Lolita teria sido escrito em 56 dias, enquanto esteve preso. H. H. escreve como se, por vezes, estivesse se dirigindo a um júri. No capítulo final, ele diz ter desistido de apresentar o livro no julgamento e que "sua publicação precisará ser adiada", só devendo ocorrer após a morte de Lolita (NABOKOV, 2011, p. 359). Mas é altamente contestável essa afirmação de H. H. de 
que ele estivesse escrevendo essas memórias para apresentar a um júri durante um julgamento por assassinato, bem como que ele o tenha escrito nesses 56 dias. No nível intradiegético, isto é, se analisarmos o que H. H. escreveu em Lolita, veremos como suas afirmações muitas vezes são dúbias, ao mesmo tempo em que ele se dá ares de exercer um controle seguro da narrativa. Por brevidade, me aterei, inicialmente, apenas ao problema dos 56 dias, que, analisando-se corretamente o texto, só poderiam ter sido 51.

Em minha análise, posso começar por separar, ainda que a fronteira nem sempre seja clara, entre "problema textual" e "problema interpretativo". Um problema textual é uma questão que busca a resposta no que está, ou não, escrito no texto; assim, a resposta poderá ser objetiva e satisfatória ou apenas parcial. Por exemplo, estabelecer a cronologia dos acontecimentos em Lolita é um problema textual: pode ser possível compor uma linha de tempo completa em que os acontecimentos se sucedem ou pode ser que não se consiga senão uma linha parcial, com lacunas; também é possível que haja contradições. No entanto, pôr a questão de por que a linha de tempo é incoerente e o é neste ou naquele momento é propor uma pergunta que abre um problema interpretativo. Enquanto um problema textual pode ou não ser respondido, enquanto é possível ou não encontrar elementos para compor uma resposta completa, sendo possível também que a resposta seja lacunar ou mesmo indecidível entre duas opções, já o problema interpretativo provoca linhas de interpretação que não precisam ser binárias, nem mutuamente excludentes. Zimmer (2008), buscando responder a questão da cronologia de Lolita, indica que, da prisão de Humbert em 26 de setembro até o dia de sua morte em 26 de novembro, ele só teria 51 dias, e não 56 dias, para escrever o livro. A inconsistência sobre o tempo - considerando-se isso como sendo apenas um problema textual - poderia ser justificada como um lapso devido a seu estado mental (além de ele já ter se mostrado por vezes, digamos, negligente em vários outros trechos de Lolita, bem como devido ao fato de que ele não disporia na prisão de fontes de consulta adequadas); em todo caso, todos os afazeres que sua estada, primeiramente, na clínica e sua posterior mudança para a prisão, com inúmeros interrogatórios e restrições quanto a que material ter em mãos, bem como horário para apagar as luzes, certamente impediriam que ele redigisse um livro tão

8 "It took Nabokov almost three years of hard work to write the book and he was surely aware that he was imposing an impossible task on Humbert when he made him write it about forty times as fast - and that some readers would volumoso e intrincado (ao qual Nabokov dedicou três anos de trabalho em condições muito mais tranquilas). ${ }^{8}$ Zimmer indica que essas incoerências levaram a que alguns críticos considerassem que Humbert nunca teria nem ido até Coalmont, onde ele reencontrou Lolita (e ela lhe revelou com quem ela havia passado a viver ao abandoná-lo), mas que teria começado a escrever suas memórias muito antes, em casa, em alguma clínica psiquiátrica, 
em um diferente período prisional ou em qualquer outro lugar, mas não no modo como ele descreve; em consequência, os capítulos finais deveriam ser entendidos como "uma invenção dentro de uma invenção". ${ }^{\prime}$ Zimmer prefere, no entanto, considerar que Humbert teria sido preso e estaria esperando o julgamento quando escreveu suas memórias; no entanto, ele considera que

9 "Several critics have understood this to imply that he never went to Coalmont but instead began penning his memoir, at home or in a psychiatric clinic or in jail or anywhere - and that hence all the events after September 21 must be fictional in the second degree, an invention inside the invention." (ZIMMER, 2008)

10 "I personally find it tempting to believe that he "really" is "in legal captivity" and that he "really" didn't have more than 51 days to complete his book, but that most of it had been written before his arrest, during the three years after Lolita's disappearance. In this case all he had to do in prison was to go over the whole of it once more, to insert the covert allusions to the identity of his foe and to append what happened after he had received Lolita's letter. Incidentally this would explain why he is repeatedly quoting from material he will hardly have had access to during his imprisonment. It would also help explain his seemingly sudden shift of stance which some critics have found unconvincing." (ZIMMER, 2008).

11 Explicar um romance tido como realista a partir desses pressupostos é um ponto de vista válido; de fato, é, pelo menos inicialmente o que tanto o leitor treinado quanto o amador busca. Por isso, sendo Lolita um livro, em geral, tido como basicamente realista, são exatamente esses pressupostos, essa busca em explicitar a coerência realista, que, para o benefício dos estudantes, são adotados grande parte do texto havia sido escrito anteriormente e que ele teria apenas completado a parte final e o revisado em seu todo. ${ }^{10}$

O problema da incoerência na cronologia no texto de Lolita provocou - e nisso o problema textual torna-se um problema interpretativo - duas linhas de interpretação: uma, a de Zimmer (2008), que mantém que a narrativa de Humbert foi completada na prisão, após ele haver assassinado Clare Quilty, e outra, que considera que o texto de Lolita foi escrito fora da prisão ou, ao menos, não nesse período prisional devido ao assassinato de Clare Quilty, tal como está em Lolita, pois esse final seria "uma invenção dentro da invenção". De certo modo, essas duas interpretações são indecidíveis: fica a gosto de cada um escolher a mais plausível para si.

Essas interpretações têm, porém, um pressuposto em comum: as duas afirmam a realidade ficcional do texto de Lolita, isto é, que existe uma coerência na narrativa que a equipararia em credibilidade (ainda que se trate de uma, por assim dizer, credibilidade ficcional) a histórias reais ou a relatos jornalísticos. ${ }^{11}$ Essas interpretações, entretanto, só discordam quanto ao final. Até, digamos, o capítulo 27 da Parte 2, quando Humbert teria recebido a carta de Lolita, apesar de uma ou outra inconsistência de datas, de menor importância, tudo teria realmente se passado como relatado, ou seja, tudo teria realmente se passado ficcionalmente. Poderíamos até assumir que, até aquele capítulo, Nabokov teria conseguido expor com maestria a mente, no caso, a escrita de um psicopata. Depois, ou ele teria, basicamente com a sua esmerada competência, conseguido completar - em 51 dias - os capítulos finais, tal como entende Zimmer, ou teria recorrido a uma questionável "invenção dentro da invenção". Além disso, para essas duas interpretações, que buscam sustentar a realidade ficcional do texto de Lolita, é muito conveniente que o manuscrito tenha sido trabalhado fora da prisão, porque só assim é possível explicar como $\mathrm{H}$. H. cita de fontes das quais ele não disporia na prisão, como seu diário em Ramsdale ou a carta de Charlotte propondo casamento, bem como lembrar o nome e o trajeto das viagens.

De fato, os capítulos finais, de 28 a 35, segundo Zimmer, foram contestados porque, neles, segundo alguns críticos, Humbert apresentaria uma mudança de atitude pouco convincente, transformando-se de um "malicioso egomaníaco" em uma pessoa sensível para com os outros - para com a Lolita - e com desgosto por si próprio. Porque essa mudança foi tão repentina, 
Zimmer a reivindica como um argumento a favor de sua interpretação, que põe Humbert na cadeia como um assassino, e, assim, contrário à interpretação que põe Humbert escrevendo por até três anos (desde a fuga de Lolita), o que o faria ir mudando aos poucos ao longo da redação do texto. Zimmer também indica que, se per impossibile o texto de Lolita tivesse sido escrito todo na prisão, a "epifania final", após a conversa em Coalmont até o assassinato de Quilty, teria afetado a escrita do texto desde o início (ZIMMER, 2008). ${ }^{12}$

No entanto, tanto a incoerência do tempo de escrita do texto quanto a mudança de atitude de Humbert me levam a propor mais uma linha de interpretação. Minha interpretação é a de que o texto de Lolita trabalha contra a aceitação de que o texto possa ter sido escrito por $\mathrm{H}$. $\mathrm{H}$. não só na prisão, não só fora da prisão, mas que possa ter sequer sido escrito intradiegeticamente por Humbert Humbert, quer dizer, pelo autor que assumiu esse pseudônimo, enquanto um texto autobiográfico ficcional. Ou seja, a minha interpretação postula por trás de $\mathrm{H}$. H. - que reivindica que sua escrita é imanente à narrativa - um autor $X$, fundamentalmente independente da narrativa, que escreveria Lolita controlada e planejadamente, além de deixar rastros que apontam para seu lugar autoral extradiegético. Segundo minha interpretação, qualquer uma das duas interpretações acima, resultantes dos esforços de seus hábeis e imaginativos críticos para manterem a realidade ficcional da narrativa do relacionamento afetivo-sexual entre H. H. e Lolita intacta (ao menos até o referido capítulo 27), são, em aspectos importantes, insuficientes. Esse escritor, que escreve desde esse lugar autoral extradiegético, podemos por ora continuar a denominar escritor $X$ (que não assumo como necessariamente sendo diretamente Nabokov), que teria conduzido, por detrás de seu personagem ficcional $\mathrm{H}$. $\mathrm{H}$., a narrativa de Lolita teria sido realmente magistral, embora tenha incorrido - o que, a meu ver, é muitas vezes o momento mais importante da escrita literária (se é que tal coisa, a escrita literária, é, de algum modo, possível) - em um risco que, para nós, num olhar retrospectivo, pode, falsamente, parecer apenas

12 "But if one assumes that he had three years to effect this change, three years to review his case by writing it down, starting with the final epiphany when looking down on that town in the mountains..., his turn to moral standards would come as less a surprise. And if he had written much of his memoir before, he would not have needed to effect his change of viewpoint during the writing and write um risco calculado; no entanto, esse risco, o risco do livro não ser publicado ou permanecer obscuro devido a sua publicação por uma editora menor ou de fora dos Estados Unidos - para cujo público ele foi escrito ao longo de três anos de trabalho tenaz -, era um risco considerável, ainda que bem menor após a sentença de 1933, referida no prefácio de Lolita, em favor do Ulysses.

Para que eu possa me explicar mais facilmente, retornarei a $\mathrm{H}$. H. Ele, sem dúvida, conduz habilmente a narrativa. Seu livro começa com o canto das sereias: "Lo-Li-Ta", o nome "Lolita", que, no prefácio (que pode, no entanto, ter sido escrito e anteposto à narrativa pelo próprio $\mathrm{H}$. $\mathrm{H}$.), sob o nome de John 
Ray, é proclamado como sendo verdadeiro; nesse gesto, $\mathrm{H}$. $\mathrm{H}$. seduz os leitores para dentro da realidade ficcional, enfim, com esse canto, os leitores estabelecem um pacto ficcional segundo o qual lerão a narrativa como sendo a exposição minuciosa e verdadeira de uma mente perversa. De fato, a realidade ficcional é construída com inúmeros pormenores que sugerem fortemente sua veracidade. Quanto ao uso da língua inglesa por parte de um suíço, não há nenhum problema, pois $\mathrm{H}$. $\mathrm{H}$. se descreve como dedicado escritor e professor, tendo escrito uma história comparada da literatura francesa e inglesa, em dois volumes, o que garante seu domínio da língua inglesa; sendo que, tal como que por precaução, Ray já relatou que corrigiu os solecismos mais óbvios. Na verdade, embora eu não seja um native speaker, minha impressão da escrita de Humbert é a de quem prazerosamente ostenta seu domínio gramatical e vocabular da língua inglesa; sinto um toque de pedantismo, que, aliás, ele - autoironicamente? - parece reconhecer numa frase como: "disse eu em meu inglês horrivelmente cuidadoso" (NABOKOV, 2011, p. 326); no entanto, seu vício de estilo mais evidente é o de esparramar excessivamente diversas referências culturais européias, a ponto de escolher como nome de casada de Lolita nada menos do que "Schiller" (que seria um nome apenas para mascarar a verdadeira identidade dela). No entanto, esses, por assim dizer, "solecismos" culturais poderiam passar como sendo adequados a um europeu erudito. Sim, poderiam, mas, sendo X um escritor tão hábil, tudo isso pode ser uma encenação: um americano escreveria em um sofisticado pastiche de inglês com solecismos culturais e com um "inglês horrivelmente cuidado" para se passar por um europeu pedante, disfarçando sua autoria com um pseudônimo absurdo. E nada impede que $X$ seja um russo, que escreve como sendo um americano que imita um europeu culto (um suíço, que seja), que recorre a um pseudônimo para assinar o corpo de um livro, cujo prefácio (também escrito por $\mathrm{H}$. $H$., ou por $X$ ?) deveria confirmar a realidade ficcional da escrita de $\mathrm{H}$. H., atando os leitores em um pacto ficcional em que eles lerão tanto como se vislumbrassem uma mente perversa quanto se presenciassem um embate entre duas culturas: a européia erudita e decadente e a americana vivaz mas já corrompida (e, dependendo do juiz, também já corruptora). Nesse sentido, o prefácio, que esboça um sem número de acontecimentos e tece alusões, de início, incompreensíveis, seria um nevoeiro ("Haze", que, aliás, rima com "maze") pelo qual os leitores entram no livro até serem resgatados do prefácio ao passarem a serem conduzidos pelo canto "Lo-Li-Ta" do início do primeiro capítulo. Daí para frente, Humbert Humbert será, aparentemente, o timoneiro.

No entanto, voltemos ao que o texto de Lolita nos diz literalmente. Quem é, segundo o próprio texto, o primeiro leitor de 
Lolita? É Charlotte Haze, a mãe de Lolita. Ela teria lido trechos do mesmo diário que é "transcrito" no capítulo 12 da Parte I (NABO$\mathrm{KOV}, 2011$, p. 49-66). Ela se desespera ao ler sobre a suposta paixão de Humbert por Dolores e, embora $\mathrm{H}$. H. tenha explicado a Charlotte que aquelas anotações que ela encontrara eram apenas "fragmentos de um romance", nos quais os nomes de Charlotte e da filha apareceriam "por mero acaso", ela continuou perturbada e, ao sair na rua, foi atropelada e morreu (Idem, p. 114).

Charlotte foi a primeira leitora de Lolita, mas não só isso: ela pode também ser entendida como uma metonímia do público americano que viria a ler um livro escrito a partir daqueles "fragmentos de romance". Era esse público (que, apesar da mencionada sentença de Woolsey tolerando o artístico, não tendia, na prática, a aceitar tais escusas jurídicas) que $\mathrm{H}$. H., ou X através de $\mathrm{H}$. H., teria de enfrentar para fazer com que seu romance, seu "opus", triunfasse na América. De fato, uma longa jornada se lhe antepunha.

Como o texto de Lolita expõe esse público-Charlotte? Não seria um público submisso, ainda que talvez afeito a ter princípios. De fato, o autor reconhece que, "[c]omedida e americana, Charlotte me metia medo", porque ao compará-la a Valerie, sua primeira esposa em Paris, a quem Humbert dava ordens e até batia, tinha de reconhecer que Charlotte não aceitaria intromissões no modo como ela decidia tratar sua filha (NABOKOV, 2011, p. 99). H. H. se mostra consciente de que, se ele tentasse impor alguma coisa a Charlotte sob a ameaça de separar-se dela, ela diria "...chegamos ao fim" (Idem, p. 100). Ele se declara francamente contrariado com "...essas mulheres de princípios" (Idem, p. 99). No entanto, ele considera também que Charlotte "não percebia a falsidade sistemática das convenções cotidianas, das regras de comportamento, da comida, dos livros e das pessoas que [ela] tanto admirava..." (Ibidem, p. 99). Charlotte, e portanto o público americano em geral, faria parte da "era da classe média enxerida" ("middle-class nosy era") (Idem, p. 104). E é frente a essa classe média enxerida que o autor de Lolita defende seu caso. Ao longo do livro, ele se refere, por vezes, ao júri : "Senhoras e senhores do júri" (Ibidem); primeiramente, o leitor entende que seria Humbert preparando suas memórias para usar em seu julgamento. De fato, é uma leitura possível, mas, se pensarmos que um romance é, por assim dizer, julgado pelo público, então seria não exatamente a um grupo de pessoas com encargos judiciais legalmente estabelecidos que $\mathrm{H}$. H. estaria se dirigindo, mas a essa "classe média enxerida". Mas, afinal, o que é um júri? Que pessoas o compõem? Um júri é basicamente composto por pessoas respeitáveis, escolhidas entre a população em geral, ou seja, um júri é um grupo composto a partir da classe média enxerida. E, de fato, o júri é um bando de enxeridos que aceita julgar a vida dos outros com base em padrões 
legais e morais, padecendo, portanto, das mesmas limitações já atribuídas a Charlotte: não perceber "a falsidade sistemática das convenções cotidianas, das regras de comportamento, da comida, dos livros e das pessoas". Lolita é um texto que, tal como H. H. se diverte zombando dos psiquiatras, escarnece dessa classe média enxerida. No entanto, para não me estender demais, considerarei apenas a incapacidade desses enxeridos em perceber a "falsidade sistemática" dos livros, no caso, do próprio texto de Lolita.

Para isso, vou comentar apenas um nome "Vivian Darkbloom", que aparece tanto no corpo do livro quanto no prefácio. Vivian Darkbloom é um nome que aparece em sua forma completa três vezes ao longo de Lolita - uma delas no prefácio, de John Ray -, e ainda mais duas vezes apenas como "Vivian". Ela é, em Lolita, uma escritora, casada com Clare Quilty, e que, segundo Ray menciona, escreveu um livro sobre a vida de seu marido, que, na opinião dos críticos, seria o melhor livro dela. Humbert, após haver assistido com Lolita uma peça de teatro na cidade de Wace, durante a segunda viagem deles pelo interior dos Estados Unidos, vê de relance o casal coautor da peça; no entanto, Lolita o corrige dizendo que "Vivian é o homem dos dois escritores, e a mulher é Clare" (NABOKON, 2011, p. 258). Esse episódio seria uma explicação de por que Humbert nunca suspeitou que Clare Quilty poderia ser quem "raptou" Lolita do hospital. No entanto, ele nunca suspeitou também de Vivian Darkbloom, que supunha ser um homem. De certo modo, apesar da paranoia de perseguição de Humbert, que o fazia suspeitar de todos os homens, Vivian permanece acima de qualquer suspeita.

Humbert só destroca os significados desses dois nomes que, em inglês, são andróginos, muito mais à frente na narrativa, quando, aliás, uma outra palavra, "waterproof", é mencionada mais uma vez no romance. A palavra "à prova-d'água" ("waterproof") só aparece duas vezes em Lolita: uma discretamente, sem suscitar maiores emoções nem nos personagens nem no leitor, mas, numa segunda vez, ela assume para o narrador, H. H., uma força epifânica. A primeira ocorrência da palavra "waterproof" se dá quando Humbert e Charlotte vão a um lago de nome Hourglass Lake (Lago da Ampulheta). Depois de os dois haverem nadado, aparece Jean, uma amiga do casal, e diz ter reparado que Humbert entrou na água usando relógio. Foi então explicado a ela: "À prova-d'água" ["waterproof"], disse baixinho Charlotte, fazendo boca de peixe" (NABOKOV, 2011, p. 105). Depois disso, a conversa continua, mas Jean é interrompida quando seu marido, John Farlow, chega; ela estava prestes a contar uma história sobre o sobrinho do dentista Ivor Quilty: “Da última vez ele [Ivor Quilty] me contou uma história absolutamente indecente sobre o sobrinho dele [Clare Quilty]. Parece..." (Idem, p. 106). Assim, sem nada de especial para um leitor de primeira viagem, apenas como uma discreta piada sobre 
Humbert, um representante do Velho Mundo, estar nadando no Lago da Ampulheta com um moderno relógio à prova d'água, se encerra o capítulo. "Waterproof" só reaparecerá no final do livro, quando H. H. se encontra com Lolita, agora casada e grávida, e pergunta quem a levara do hospital, enfim, qual o nome desse amante que a roubou dele, nome que ele nunca conseguira descobrir. Humbert, sem a princípio mencionar o nome, descreve como Lolita respondeu:

E em voz baixa, num tom confidencial, arqueando as finas sobrancelhas e franzindo os lábios ressecados, emitiu, com uma expressão um tanto zombeteira e um pouco entediada, não desprovida de alguma ternura, numa espécie de assobio mudo, o nome que o leitor astuto já deve ter adivinhado há muito tempo. (NABOKOV, 2011, p. 317 - o grifo é meu)

E o parágrafo seguinte começa com a palavra: “À provad'água" ["waterproof"]. Esta palavra seria como que um eco na mente de Humbert, não um eco exato do que Lolita falou, mas, digamos, um eco interpretativo. $\mathrm{O}$ nome que ela falou, o que fica claro na sequência do diálogo, deve ter sido "Clare", Quilty" ou "Clare Quilty".

Humbert narra sua reação ao ouvir o nome: "Por que um relance do Lago da Ampulheta atravessou minha consciência? Eu também sabia, sem saber, desde sempre." Ele acabara de se lembrar de Jean mencionando uma "história absolutamente indecente" a respeito do sobrinho - portanto, de um homem - do dentista, dando-se conta, assim, de que sempre soube quem fora o, digamos, indecente que levara Lolita embora. Talvez Lolita o tenha enganado dizendo-lhe que Clare Quilty era uma mulher, mas ele sempre já o teria sabido: teria sido ele mesmo que se levou a se enganar. Teria sido por isso que Vivian Darkbloom permaneceu pairando acima de qualquer suspeita? Ou será que também se trata de um nome que nos engana? Se somos, como é mencionado na extensa passagem que citei acima, o "leitor astuto" ["astute reader"], que, segundo H. H., já teria se dado conta de quem teria "raptado" Lolita, de que maneira o nome da esposa, tal como o do marido, pode nos enganar?

Humbert parece estar elogiando alguns leitores que seriam mais astutos do que ele. Lendo essa passagem, o "leitor astuto" tenderia a se lembrar da cena do lago (ou voltaria as páginas do livro até a cena do lago) e constataria que nela Humbert ouvira falar pela primeira vez do comportamento indecente do sobrinho de Ivor Quilty. De fato, o leitor precisa de alguma astúcia para ligar uma passagem com a outra. Segundo o Sparknotes (2011), que busca propor uma interpretação básica de Lolita, ou seja, uma interpretação que sustente sua realidade ficcional, o "leitor astuto" não se atém apenas ao conteúdo narrativo, mas deixa-se participar em jogos linguísticos e guiar-se pelos 
padrões narrativos, de modo que, de fato, já teria há muito se dado conta do nome em questão. ${ }^{13} \mathrm{H}$. H. estaria, portanto, nos elogiando por desempenharmos bem a tarefa de explicitar a coerência da realidade ficcional da narrativa. A ludicidade das palavras, a repetição de "waterproof", é, de fato, um prazer a mais, uma leitura intelectualmente sofisticada, mas deixar-se levar por esse deleite estético é cessar o questionamento de se há lacunas ou fissuras na realidade ficcional, ou seja, assim, o "leitor astuto" decide-se por não chegar a vê-las e de pensar esteticamente suas consequências. O prazer do leitor astuto, sua astúcia, está em manter-se iludido quanto à coerência realista da narrativa. Na verdade, o "leitor astuto" chega a uma conclusão com fumos de paradoxo: o romance é realisticamente coerente em sua narrativa ficcional e é elaboradamente coerente em sua construção narrativa, ou seja, o romance retrata a realidade com coerência e é formalmente bem composto. Curiosamente, é a palavra "waterproof" que, ao levar o leitor astuto ao insight da tensão entre realismo e formalismo em Lolita, faz "vazar" o olhar do leitor para detrás da trama, para a cuidadosa e controlada composição da narrativa, ao mesmo tempo em que a voz autoral põe em destaque esse lugar de escrita e leitura que transborda a narrativa, que "vaza" para o espaço extradiegético.

Lolita é um romance meticulosamente montado. A própria mudança nas atitudes de Humbert, o que parece implausível a alguns críticos, está claramente articulada no romance. No capítulo 27 da Parte II, Humbert recebe duas cartas. A primeira que ele leu era de John Farlow, marido de Jean na história do lago, e falava de sua vida após a morte da esposa. O que se passa é que ele mudou em vários aspectos; e H. H. comenta: "Muitas vezes reparei que tendemos a atribuir aos nossos amigos a estabilidade de tipo que os personagens literários costumam adquirir no espírito do leitor" (NABOKOV, 2011, p. 309). Ora, o autor de Lolita, ao narrar a mudança impressionante de comportamento de John está não só exemplificando, mas também avisando que Humbert mudará de uma maneira que surpreendentemente contrariará essa tal tendência a atribuir estabilidade aos personagens literários. A frase citada logo acima é, portanto, um alerta duplo: (1) Humbert é um personagem literário (2) e ele, apesar de isso contrariar os leitores da classe média enxerida, vai mudar de um modo que irá contra a estabilidade que, a essa altura do romance, certamente já se encontra "no espírito do leitor".

Esse controle da narrativa que $\mathrm{H}$. H., por diversas vezes, ostenta ao longo de sua narrativa, se, por um lado, parece reforçar a hipótese de que a escrita de Lolita é imanente - intradiegética - à sua narrativa, por outro, sugere também que o texto foi escrito calculadamente, fora dos percalços narrados. Ora, é claro que Lolita foi escrito por Nabokov, vivendo longe das peripécias de Humbert. O que está em questão para nós é se a 
narrativa de Lolita indica intradiegeticamente que ela foi escrita extradiegeticamente. A questão seria, portanto, a de se o texto de Lolita indica, nele mesmo, que há um escritor X que o escreveu independentemente de ter participado de sua narrativa.

Segundo Ray, esse escritor $X$ teria de estar incluído na narrativa, porque Ray considera que é necessário que tenha ocorrido a "calamidade" do relacionamento sexual de um homem de 37 com uma menina de 12 para que o livro Lolita pudesse ser escrito. No entanto, podemos, com o privilegiado do nosso ponto de vista extradiegético, contra-argumentar que, ao que se sabe, Nabokov não cometeu tal "calamidade" e pôde escrever Lolita, assim também o escritor X (ainda que considerado um personagem-escritor que Nabokov teria deixado permanecer anônimo), também poderia ter escrito o livro, atribuindo-o a Humbert sem ter cometido a "calamidade". Mas X pode também ser diretamente Nabokov. Se bem que, o que me parece uma hipótese mais plausível, é que Nabokov teria posto para escrever Lolita um personagem $\mathrm{X}$, que seria um europeu expatriado, tal como se ele, Nabokov, a essa altura de sua estada nos Estados Unidos, já tivesse se tornado americano demais para ser ele mesmo um europeu erudito escrevendo. Nesse sentido, Lolita seria um livro extremamente americano, não só pelas múltiplas referências à cultura e à vida americanas, mas pelo esforço que Nabokov talvez tenha de ter feito para escrever (burlescamente?) como se fosse um europeu.

Seja como for, "waterproof" - porque reforça no leitor astuto o entendimento da extrema elaboração narrativa de Lolita, bem como porque é o escritor do texto que chama atenção para isso, para sua perícia, para seu domínio do texto - debilita em muito a credibilidade da hipótese de que o livro teria terminado de ser escrito na prisão, que, até aqui, era a hipótese mais forte para salvar a realidade ficcional, isto é, a consistência realista da narrativa. Ao contrário, frente a "waterproof", a hipótese de que Humbert, ao longo do período afastado de Lolita, e até mesmo sem ter cometido o assassinato, escreveu - e avisa que escreveu - esse texto formalmente elaborado ganha força como argumento para que ainda seja possível sustentar convincentemente a realidade ficcional. É curioso que a partir do problema interpretativo devido à inconsistência do tempo de escrita de Lolita, tínhamos a hipótese "c", segundo a qual o livro teria sido escrito em casa ou em uma clínica psiquiátrica como sustentando mal a realidade ficcional, pois não explicava bem a mudança abrupta de atitude de Humbert, cuja transformação deveria ter se dado mais lentamente, durante o longo período de escrita do texto. Frente à hipótese " $\mathbf{c}$ ", " $\mathbf{b}$ ", que propunha que H. H. apenas terminou de escrever Lolita na prisão, parecia mais forte. Agora a hipótese "a", segundo a qual um escritor X (ficcional ou não), fora da trama, é que teria escrito o livro e faz questão de indicar 
sua presença ao fazer o texto vazar com "waterproof", se mostra uma hipótese forte, mas que pode ser questionada, porque, de certo modo, a hipótese " $c$ " pode incluí-la ao alegar que Humbert estaria construindo um texto com paranoicas associações de palavras e autoincriminações delirantes. Desse modo, teríamos em termos de força explicativa $\mathbf{b}>\mathbf{c}$, e $\mathbf{a}>\mathbf{b}$, o que levaria $\mathbf{a} \mathbf{a}>\mathbf{b}>\mathbf{c}$, o que, porém, após "waterproof", não impediria que, em certa medida (no caso, adotando-se a hipótese de que H. H., em algum hospital, está escrevendo um delírio sistemático autorreferente), se aceite também c>a, o que nos levaria, como um efeito da conjunção de problemas interpretativos, a termos de aceitar, quanto à plausibilidade, tanto $\mathbf{a}>\mathbf{b}>\mathbf{c}$ quanto $\mathbf{c}>\mathbf{a}$. É porque "waterproof" e "56 dias" são problemas interpretativos, ou seja, elementos narrativos indomáveis enquanto proliferadores de hipóteses interpretativas, que, por seus efeitos múltiplos, não devem ser encarados apenas como problemas textuais, que, quando muitas informações podem ser coletadas no texto, poderiam ser respondidos satisfatoriamente; problemas interpretativos podem, ao contrário, ser potencializados na medida em que mais informações emergem da leitura detalhada do texto.

No entanto, ainda assim, ameaçando ferir profundamente a realidade ficcional, temos o já referido problema interpretativo: "Vivian Darkbloom". A questão que se impõe com esse nome é que ele é um anagrama de "Vladimir Nabokov".14 Baseandonos no texto de Lolita, cabe perguntar como Humbert - ou John Ray - teriam elaborado esse pseudônimo em anagrama senão se conhecessem Nabokov (o que, de fato, não é mencionado nem no prefácio nem na narrativa)? Ora, além de artistas da cultura popular americana e de escritores internacionalmente reconhecidos (Proust, Joyce, Flaubert e outros), Humbert cita os artistas que se apresentam em sua narrativa, artistas dos quais ele teria trocado os nomes para evitar reclamações. Vivian seria uma escritora que teve seu nome mudado, mas de onde teria vindo o nome de Vladimir Nabokov, não sendo ele nem um artista popular americano nem, na época, um nome internacionalmente famoso tal como Proust e Joyce? Tampouco, em Lolita, é generalizada a prática de nomes que são anagramas. Mais uma vez temos uma palavra que faz o texto "vazar" para fora dele, e agora vaza não somente de modo a se poder postular um autor $X$ por trás de Humbert, mas, inevitavelmente, chega-se a Vladimir

${ }^{14}$ Não está em questão neste artigo o uso de anagramas nas obras de Nabokov, mas somente o do anagrama de Vladimir Nabokov na temática em discussão, a saber, sobretudo na questão do processo de publicação intradiegético. Nabokov. (Nem é possível alegar aqui que elaborar anagramas seja uma prática paranoica - como a hipótese $\mathbf{c}$ acima - porque $\mathrm{X}$ teria de conhecer e mencionar Vladimir Nabokov, o que não seria um delírio.) De certo modo, essa autopromoção do próprio nome, que, pela sua história literária até então, bem como com a comparação com Joyce feita por Ray, poria Nabokov na galeria dos grandes escritores que Humbert cita vale como uma aposta por parte do próprio Nabokov de que ele, quem sabe, com o livro 
Lolita mesmo, finalmente chegaria a ser visto como sendo da mesma estatura deles. De fato, essa aposta de Nabokov quanto ao notável reconhecimento que sua "biografia" de H. H. alcançará ao ser "publicada em breve" está claramente assinalada, por meio de uma "deixa" (em inglês, em linguagem teatral seria "cue"), no prefácio: “'Vivian Darkbloom' [Vladimir Nabokov!] é autora ["the autor"] de uma biografia, Minha deixa ["My Cue"], a ser publicada em breve, e os críticos que folhearam os originais classificaram-na como o melhor de seus livros" (NABOKOV, 2011, p. 8 - os grifos em negrito são meus). ${ }^{15}$

Visto assim, Lolita seria a história de uma aposta literária consciente e ousada, que foi amplamente ganha. O lolitismo seria apenas o canto das sereias para que o público, o tal público classe média enxerida, em meio à névoa de uma narrativa em diversas camadas, fosse conduzido através da cuidadosa composição da narrativa e suas estratégicas transgressões de convenções sistemáticas. Nabokov, com sua narrativa multifacética, teria jogado para duas platéias. Em Lolita, literariamente considerado, as convenções narrativas que sustentam a realidade ficcional do relato supostamente autobiográfico de um suposto europeu supostamente pervertido são, por um lado, diligentemente seguidas, envolvendo os leitores num prazer que, segundo as convenções vigentes, seria aceitavelmente transgressivo (ou, si vous voulez, aceitavelmente sensacionalistas); por outro, essas convenções são contrariadas, o que se dá quando, insidiosamente, vão surgindo fissuras na realidade ficcional até o ponto de desautorizar Humbert como narrador autobiográfico, estabelecendo uma autoria por detrás dele, que o remete - e assim o anula -, através sobretudo de "Vivian Darkbloom", a Vladimir Nabokov, que, por sua vez, ao distanciar-se, por meio do prefácio de Ray e do pseudônimo de Humbert Humbert, conseguiu esse amainamento do suposto realismo da narrativa - sem que a narrativa perdesse, aos olhos de tantos milhares de leitores, seu caráter realista ficcional -, sendo que, no mesmo gesto, conseguiu ainda a valorização do caráter artístico do texto, o que, apesar de várias proibições de publicação fora dos Estados Unidos, acabou conduzindo Lolita a um estrondoso sucesso de público e crítica. Digamos que, com Lolita, Nabokov alcançou, o que sempre é extremamente difícil, o melhor dos dois mundos, do popular e do erudito, ao mesmo tempo em que contribuiu para desmontar essa dúbia polaridade (que, contudo, não deixa de ter fundamentado a sentença judicial que permitiu a publicação de Ulysses e, em seu rastro, de Lolita). Do mesmo modo, Lolita

${ }^{15}$ Em inglês: "Vivian Darkbloom" has written a biography, "My Cue," to be published shortly, and critics who have perused the manuscript call it her best book. conquistou o Novo e o Velho Mundo, pondo em questão se eles são, afinal, tão dicotômicos em suas inovações e perversões. Mas ler Lolita como um texto que questiona e relativiza dicotomias culturais já não é mais nosso tema. 


\begin{abstract}
This paper discusses the "act" of publishing in the broad sense as a "process" in stages that considers the education and the linguistic skills of the writer, runs the production, the printing and the distribution of the book, makes use of strategies to avoid censorship and judicial prosecution, and monitors the critics and the publics' reaction to the book; the main point of this paper, however, is the analysis of the acts of publishing and of writing as they are mentioned or hinted at in the story itself or as they are interwoven in the fictional reality. Then, beginning with a comment on the Preface of Lolita, by John Ray, Jr. ph. D., the fictional authors present argumentative strategies for the non banning of the book and point out relevant aspects of the intricate relationship between, on one hand, John Ray and Humbert Humbert, two writers who are immanent in the narrative web, and, on the other hand, the signatory author, Vladimir Nabokov, bringing out, among other issues, the awareness of the boldness of his literary bet against the readership of the "middle-class nosy era" as well as of its confidence in the promising results of Lolita's publication.
\end{abstract}

Keywords: literary theory; literature and medicine; authorship; paranoia; act of reading; act of publishing.

\title{
REFERÊNCIAS
}

BOURDIEU, Pierre. As regras da arte. São Paulo: Companhia das Letras, 1992.

LAHIRE, Bernard. La condition littéraire. Paris: Éditions La Découverte, 2006.

MACHADO DE ASSIS, J. M. Obra Completa. Rio de Janeiro: Editora Nova Aguilar, 1986, vol. 1.

MICELI, Sergio. Intelectuais à brasileira. São Paulo: Companhia das Letras, 2001.

NABOKOV, Vladimir. Lolita. Rio de Janeiro: Objetiva, 2011. Lolita. New York: Random House, 1989.

RIOS, André Rangel. O ato de publicação. Rio de Janeiro: Booklink, 2007.

SPARKNOTES. Lolita Summary. (2011) http://www.sparknotes. com/lit/lolita/summary.html; acessado em: 13/6/2011.

STACH, Reiner. Kafka. Die Jahre der Entscheidungen. Frankfurt: Fischer, 2003. 
ZIMMER, Dieter E.. Lolita, USA. A geographical scrutiny of Vladimir Nabokov's novel Lolita (1955/1958). (2007) http://www.dezimmer. net/LolitaUSA/LoUSpre.htm; acessado em: 13/6/2011. A Chronology of Lolita. (2008) http://www.dezimmer.net/ LolitaUSA/LoChrono.htm; acessado em: 13/6/2011. 